\title{
Early resuscitation of dengue shock syndrome in children with hyperosmolar sodium-lactate: a randomized single-blind clinical trial of efficacy and safety
}

Dadang H Somasetia ${ }^{1}$, Tatty E Setiati ${ }^{\wedge}$, Azhali M Sjahrodji ${ }^{1}$, Ponpon S Idjradinata', Djatnika Setiabudi ${ }^{1}$, Hubert Roth ${ }^{3}$, Carole Ichai ${ }^{4}$, Eric Fontaine ${ }^{3^{*}}$ and Xavier M Leverve ${ }^{3^{\wedge}}$

\begin{abstract}
Introduction: Dengue shock syndrome (DSS) fluid resuscitation by following the World Health Organization (WHO) guideline usually required large volumes of Ringer lactate (RL) that might induce secondary fluid overload. Our objective was to compare the effectiveness of the recommended volume of RL versus a smaller volume of a hypertonic sodium lactate solution (HSL) in children with DSS. The primary end point was to evaluate the effect of HSL on endothelial cell inflammation, assessed by soluble vascular cell adhesion molecule-1 (sVCAM-1) measurements. Secondarily, we considered the effectiveness of HSL in restoring hemodynamic fluid balance, acid-base status, and sodium and chloride balances, as well as in-hospital survival.

Methods: A prospective randomized single-blind clinical trial including 50 DSS children was conducted in the Pediatrics Department of Hasan Sadikin Hospital, Bandung, Indonesia. Only pediatric patients (2 to 14 years old) fulfilling the WHO criteria for DSS and new to resuscitation treatments were eligible. Patients were resuscitated with either HSL (5 ml/kg/BW in 15 minutes followed by $1 \mathrm{ml} / \mathrm{kg} / \mathrm{BW} / \mathrm{h}$ for 12 hours), or RL (20 ml/kg/BW in 15 minutes followed by decreasing doses of 10, 7, 5, and $3 \mathrm{ml} / \mathrm{kg}$ BW/h for 12 hours).

Results: In total, 50 patients were randomized and included in outcome and adverse-event analysis; 46 patients $(8.2 \pm 0.5$ years; $24.9 \pm 1.9 \mathrm{~kg}$; mean \pm SEM) completed the protocol and were fully analyzed (24 and 22 subjects in the HSL and RL groups, respectively). Baseline (prebolus) data were similar in both groups. Hemodynamic recovery, plasma expansion, clinical outcome, and survival rate were not significantly different in the two groups, whereas fluid accumulation was one third lower in the HSL than in the RL group. Moreover, HSL was responsible for a partial recovery from endothelial dysfunction, as indicated by the significant decrease in sVCAM-1.
\end{abstract}

Conclusion: Similar hemodynamic shock recovery and plasma expansion were achieved in both groups despite much lower fluid intake and fluid accumulation in the HSL group.

Trial Registration: ClinicalTrials.gov NCT00966628. Registered 26 August 2009.

\footnotetext{
*Correspondence: eric.fontaine@ujf-grenoble.fr

Deceased

3LBFA - INSERM U1055, Joseph-Fourier University, BP 5338041 Grenoble,

Cedex, France

Full list of author information is available at the end of the article
} 


\section{Introduction}

Dengue is the most frequent mosquito-borne viral infection among human beings, with more than 50 million new infections being projected annually [1]. Although it resolves spontaneously in most cases, dengue hemorrhagic fever (DHF) and dengue shock syndrome (DSS) are among the leading causes of pediatric hospitalization. Mortality rates from $1 \%$ to $5 \%$ are frequently reported for DHF/DSS from centers experienced in fluid resuscitation, but rates up to $44 \%$ have occasionally been reported in cases of established shock [2].

The major pathophysiologic abnormality responsible for DHF/DSS is an acute increase in vascular permeability, leading to plasma leakage from the vascular to the extravascular compartment [2-5], which results in hypovolemia (biologically characterized by an hemoconcentration), responsible for a moderate to severe shock. It has been suggested that the dengue virus induces a swelling of endothelial cells [3], which may damage the tight-junction complexes, thus increasing vascular permeability. Usually, the capillary leakage resolves spontaneously by the sixth day of illness and is rapidly followed by full recovery. Microvascular permeability is intrinsically higher among children than in adults, which may explain why children are more prone than adults to DSS $[4,6]$.

Endothelial cell inflammation is responsible for a high expression of VCAM-1 at the cell surface, leading to an increase in circulating sVCAM-1. It has been proposed that circulating sVCAM-1 levels may reflect the severity of the disease $[7,8]$. Therefore, from a theoretic point of view, the optimal treatment of DSS should address both the cause (endothelial dysfunction) and its consequence (hypovolemia).

Three controlled randomized double-blind trials comparing different resuscitation fluids in children with DHF/DSS failed to demonstrate any benefit of a particular fluid [9-11]. Comparing four fluids (Ringer lactate, $\mathrm{NaCl}$ 0.9\%, dextran 70, and 3\% gelatin), Dung et al. [9] did not find any difference in terms of administered volume and shock resolution. The same result was obtained in a comparable study with a larger population [10]. However, it was noted that the early administration of colloids to the most severely affected subgroup of patients was beneficial [10]. A randomized double-blind trial comparing three fluids (Ringer lactate, 6\% dextran $70,6 \%$ hydroxyethyl starch) for initial resuscitation of children with DSS established that isotonic crystalloids (RL) were as effective as colloids for initial resuscitation of children with moderate shock [11]. Consequently, the WHO recommends that patients with DSS should benefit from an immediate volume replacement with isotonic crystalloid solutions, followed by the use of plasma or colloid solutions for profound or continuing shock [2].
Totilac is a hypertonic lactate-based solution (see Table 1). It has been shown to be able to restore hemodynamic status and improve cardiac performance [12,13]. Moreover, as compared with other hypertonic crystalloid-based solutions, lactate can be used as an energy substrate by various tissues [14]. Finally, the hypertonic lactatebased solution has been shown to be effective in treating intracranial hypertension after traumatic brain injury, with a significantly more-pronounced effect than that of an equivalent osmotic load of mannitol, suggesting that sodium lactate may have an antiedema effect per se [15].

Based on this double property (intravenous fluid and antiedema effect), the present prospective randomized study was designed to compare the efficacy and safety of Totilac with RL for resuscitation of DHF/DSS children. Our hypothesis was that sodium lactate could improve endothelial cell function and decrease capillary leakage, thus minimizing fluid overload.

\section{Methods}

Fifty children with severe DSS were enrolled in this prospective, randomized, single-blind study (see Figure 1), conducted in the Pediatrics Department of Hasan Sadikin Hospital, Bandung, Indonesia, between May 2008 and April 2009. Patients were randomly assigned to RL or hypertonic sodium lactate solution (HSL) groups. Randomization was performed independently by using a table of random numbers and balanced blocks of four, with sealed opaque envelopes sequentially numbered. The enrollment of patients was performed by the pediatrician, and the assignment to intervention, by the study coordinator.

The Ethics Committee of Hasan Sadikin Hospital had approved this protocol before the study. Informed consent had also been obtained from the patients' relatives.

The intervention period ran for the first 12 hours of treatment and was followed by a 12-hour observation

Table 1 Composition of Ringer lactate (RL) and the hypertonic sodium lactate (HSL) solution Totilac

\begin{tabular}{|c|c|c|c|c|}
\hline \multirow[b]{3}{*}{ Content } & \multirow{2}{*}{\multicolumn{2}{|c|}{$\begin{array}{l}\text { Hypertonic sodium } \\
\text { lactate } \\
\text { (HSL) }\end{array}$}} & \multirow{2}{*}{\multicolumn{2}{|c|}{$\begin{array}{l}\text { Ringer lactate } \\
(\mathrm{RL}) \\
\end{array}$}} \\
\hline & & & & \\
\hline & $\mathrm{m} M$ & $g / L$ & $\mathrm{~m} M$ & $g / L$ \\
\hline$\overline{\mathrm{Na}^{+}}$ & 504.15 & 11.50 & 130.5 & 2.98 \\
\hline $\mathrm{K}^{+}$ & 4.02 & 0.16 & 4.02 & 0.16 \\
\hline $\mathrm{Ca}^{2+}$ & 1.36 & 0.050 & 0.67 & 0.024 \\
\hline $\mathrm{Cl}^{-}$ & 6.74 & 0.24 & 109.90 & 3.90 \\
\hline Lactate $^{-}$ & 504.15 & 44.92 & 28.00 & 2.49 \\
\hline Total osmolarity (mosm/L) & \multicolumn{2}{|c|}{$1,020.42$} & \multicolumn{2}{|l|}{273} \\
\hline $\begin{array}{l}\text { Organic/inorganic osmolarity } \\
(\mathrm{mosm} / \mathrm{L})\end{array}$ & \multicolumn{2}{|c|}{$504.15 / 516.27$} & \multicolumn{2}{|l|}{$28 / 245$} \\
\hline
\end{tabular}




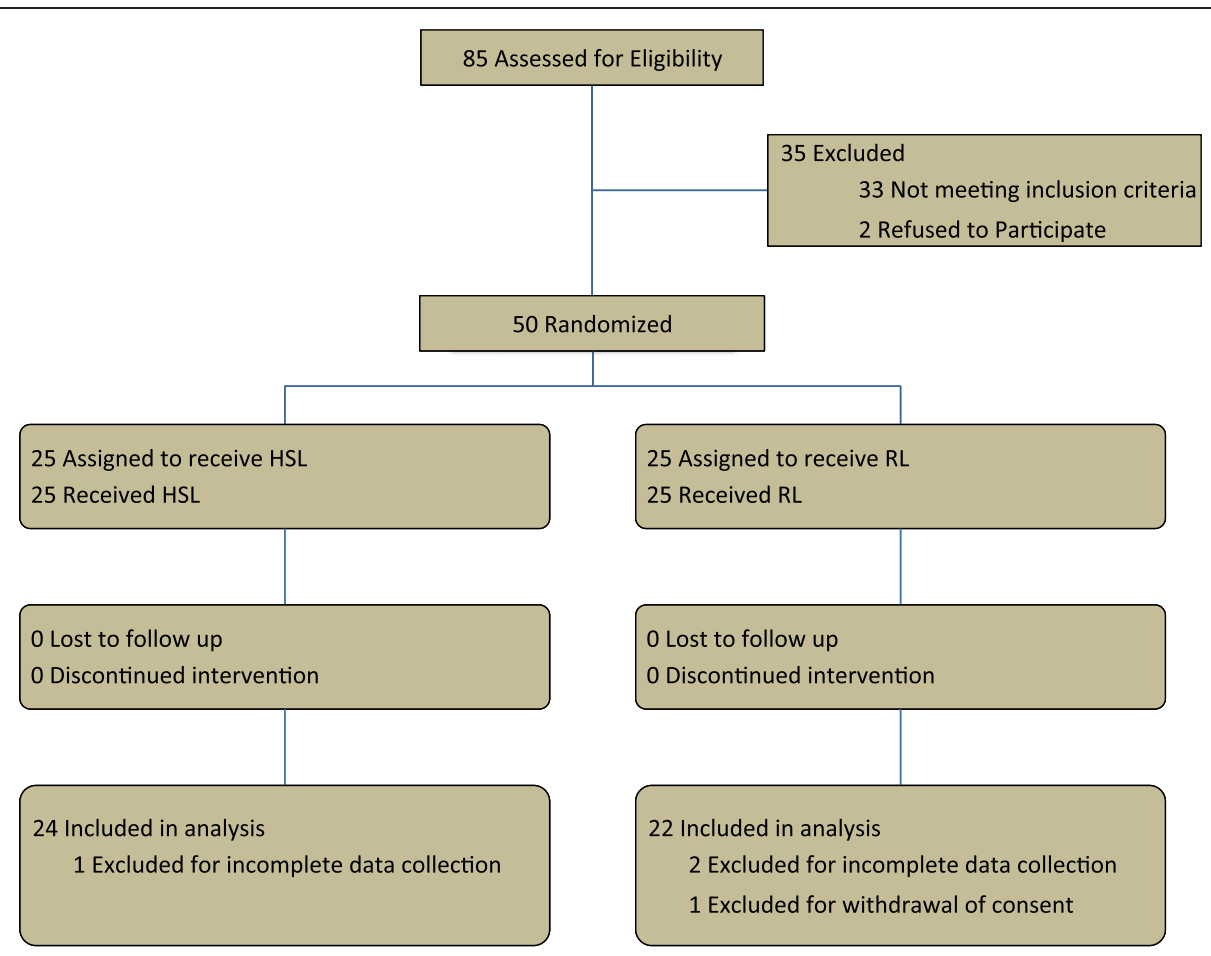

Figure 1 Profile of the randomized controlled trial.

period (see Figure 2) extended to 48 hours for sVCAM-1 measurement. The outcome, complications, adverse events, and concomitant treatments were recorded throughout the entire hospital stay until discharge. Only pediatric patients (2 to 14 years old) fulfilling the WHO criteria for DSS and new to resuscitation treatment were eligible. Based on anamnesis, physical examination, and/or laboratory tests, patients with another viral or bacterial infection, severe renal failure (creatinine $>180 \mu M$ - because of the high amount of sodium infused), chronic diarrhea (because it may influence urine output), liver failure (SGOT and SGPT > 20 times normal), severe malnutrition and diabetes mellitus (because they may change lactate metabolism), and hematologic disorders (because hemostasis was one studied parameter) were excluded.

\section{Shock management}

According to the randomization, eligible patients received an initial bolus infusion of either HSL $(5 \mathrm{ml} / \mathrm{kg}$ $\mathrm{BW}$ ) or $\mathrm{RL}(20 \mathrm{ml} / \mathrm{kg} \mathrm{BW}$ ) for 15 minutes (Figure 2). If they did not recover from the shock rapidly with the first bolus, a second loading infusion with the same solution at the same dosage was infused once again. If the second treatment failed with a persistent shock, patients received hydroxyl-ethyl starch (HES, 130/0.40) infusion $(20 \mathrm{ml} / \mathrm{kg}$ BW in 15 to 30 minutes) with a maximum dose of $50 \mathrm{ml} /$ $\mathrm{kg} \mathrm{BW}$ in 24 hours. Note that the WHO recommends colloid solutions for profound or continuing shocks, whereas HES administration was in routine practice, and concern about its safety was not reported before this study started.

If the shock was reversed, patients received a maintenance dose of the studied solution for 12 hours: $1 \mathrm{ml} / \mathrm{kg}$ $\mathrm{BW} / \mathrm{h}$ of $\mathrm{HSL}$, or decreasing doses of $10,7,5$, and $3 \mathrm{ml} /$ $\mathrm{kg} \mathrm{BW/h}$ of RL, based on patients' hemodynamic conditions (heart rate, systolic blood pressure, urine output), which corresponds to the standard protocol of DSS management in Hasan Sadikin Hospital according to the WHO recommendations. If the shock recurred within the first 12 hours, the studied solution was infused once again, as in the initial shock management. After the $12^{\text {th }}$ hour (that is, during the follow-up period), both groups received $3 \mathrm{ml} / \mathrm{kg} \mathrm{BW} / \mathrm{h} \mathrm{RL}$ according to the WHO recommendations. If the shock recurred during the follow-up period, the standard protocol of DSS management according to the WHO recommendations was applied (RL infusion with HES administration if necessary).

\section{Studied parameters}

As markers of hemodynamic status and tissue oxygenation, blood pressure, heart and respiratory rates, Glasgow Coma Scale score (GCS), body temperature, and urine output were monitored before (T0) and after 15 and then 


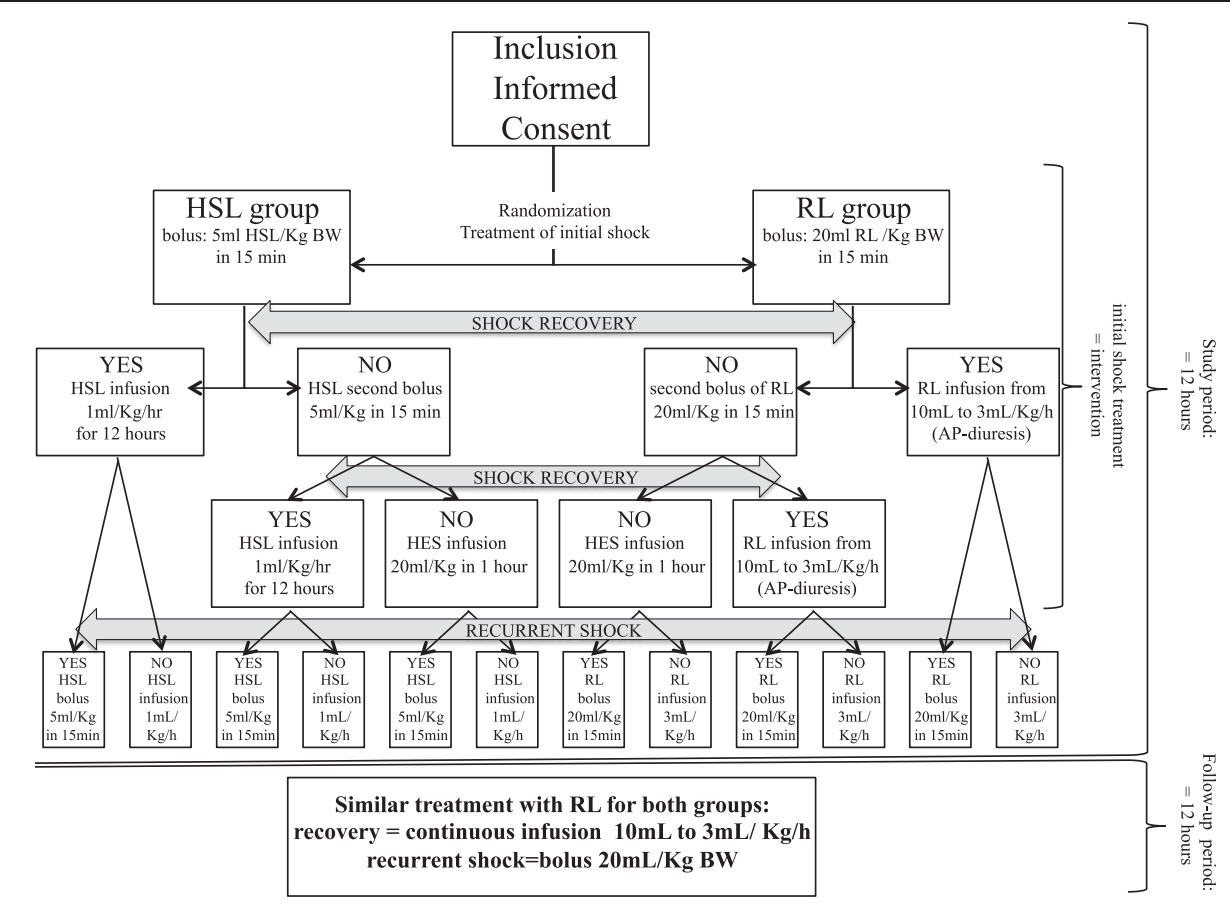

Figure 2 Study flow chart.

30 minutes, every hour until the hour 6 , and then 9,12 , 18 , and 24 hours after fluid administration.

Fluid infusion and output were measured and documented. Laboratory blood/plasma parameters including hemoglobin, hematocrit, thrombocyte and leukocyte counts, electrolytes (sodium, potassium, chloride), plasma osmolality, lactate, glucose, albumin, total protein concentrations, SGOT, SGPT, creatinine, venous gas analysis, prothrombin (PT), activated partial thromboplastin time (aPTT), fibrinogen levels, and D-dimer were determined after $0,6,12$, and 24 hours. sVCAM- 1 values were measured after 0, 24, and 48 hours with the ELISA method (R\&D Systems, Human sVCAM-1/CD106 Quantikine ELISA Kit, catalog number DVC00). Any adverse events or serious adverse events that occurred during the study period were recorded and reported for all included patients. All concomitant medications and their complement, including dosages, were also documented.

\section{Study end points}

The primary end point was the effectiveness of HSL to decrease endothelial cell inflammation assessed by sVCAM-1 measurements during the first 48 hours of DSS. Secondary end points considered the effectiveness of HSL to restore hemodynamic and tissue-oxygenation parameters, fluid balance, acid-base status, sodium and chloride balances, as well as in-hospital survival.

\section{Sample-size determination and statistical analysis}

G*Power3.1 [16] was used to calculate the sample size for a five-repeated-measure ANOVA with an alpha error of 0.05 , a power of $80 \%$, a correlation among repeated measures of 0.3 , and an effect size of 0.3 . The theoretical sample size was $n=21$ in each group. We chose to include 25 subjects per group.

Unless otherwise indicated, data are expressed as mean \pm SEM. Qualitative variables were analyzed by using the Fisher Exact test (Table 2). The effect of DSS treatment over time was analyzed with ANOVA for repeated measures, indicating the significance of the different treatments (treatment effect) and evolution (time effect) (Table 3). Data exhibiting non-normal distribution were analyzed with nonparametric unpaired (MannWhitney) or paired (Wilcoxon) tests, as indicated in the legends.

\section{Results}

\section{Studied population}

The 50 enrolled and randomized patients were included in outcome and adverse-event analysis (intent-to-treat analysis). Forty-six patients completed the protocol and were fully analyzed ( 24 and 22 subjects in the HSL and $\mathrm{RL}$ groups, respectively) whereas four patients were excluded: three for incomplete data collection and one for withdrawal of consent. As shown in Table 2, because of randomization, the two groups were not different before 
Table 2 Baseline quantitative data (mean (SEM))

\begin{tabular}{|c|c|c|}
\hline & $\begin{array}{l}\mathrm{HSL} \\
n=24\end{array}$ & $\begin{array}{l}\mathrm{RL} \\
n=22\end{array}$ \\
\hline Age, years & $8.7(0.6)$ & $7.6(0.7)$ \\
\hline Body weight, kg & $27.1(3.0)$ & $22.5(2.0)$ \\
\hline Height, cm & $126.7(4.4)$ & $118.1(3.8)$ \\
\hline Sex ratio (F:M) & $11: 13$ & $11: 11$ \\
\hline GCS & $14.4(0.3)$ & $14.8(0.2)$ \\
\hline Systolic pressure, $\mathrm{mm} \mathrm{Hg}(n=9+9)$ & $89.4(4.7)$ & $86.1(3.7)$ \\
\hline Diastolic pressure, $\mathrm{mm} \mathrm{Hg}(n=9+9)$ & $61.1(6.5)$ & $65.6(4.4)$ \\
\hline Heart rate, beats/min & $133.9(4.8)$ & $121.7(3.7)$ \\
\hline Respiratory rate, breaths/min & $34.4(2.2)$ & $33.4(1.7)$ \\
\hline Temperature, ${ }^{\circ} \mathrm{C}$ & $36.7(0.2)$ & $36.2(0.2)$ \\
\hline DHF grade III & 9 & 9 \\
\hline DHF grade IV & 15 & 13 \\
\hline Hematocrit, \% & $41.9(0.93)$ & $42.4(1.2)$ \\
\hline Hemoglobin, g/dl & $14.5(0.3)$ & $14.7(0.5)$ \\
\hline Leukocyte, $\mathrm{mm}^{-3}$ & $6,217(854)$ & $6,000(755)$ \\
\hline Thrombocyte, $\mathrm{mm}^{-3}$ & $47,042(7,693)$ & $59,409(7,421)$ \\
\hline $\mathrm{pH}$ (venous) & $7.40(0.03)$ & $7.37(0.02)$ \\
\hline $\mathrm{pCO}_{2}$ (venous), $\mathrm{mm} \mathrm{Hg}$ & $24.9(1.5)$ & $24.8(1.4)$ \\
\hline $\mathrm{pO}_{2}$ (venous), $\mathrm{mm} \mathrm{Hg}$ & $55.6(7.2)$ & $66.9(7.8)$ \\
\hline $\mathrm{CO}_{3} \mathrm{H}^{-}$(venous), $\mathrm{mM}$ & $15.2(0.9)$ & $13.8(0.7)$ \\
\hline BE (venous), $\mathrm{m} M$ & $-7.6(1.1)$ & $-10.3(0.9)$ \\
\hline $\mathrm{Na}, \mathrm{mM}$ & $129.8(1.2)$ & $128.1(0.9)$ \\
\hline $\mathrm{K}, \mathrm{m} M$ & $4.36(0.14)$ & $4.64(0.17)$ \\
\hline $\mathrm{Cl}, \mathrm{mM}$ & $94.3(1.3)$ & $95.8(1.1)$ \\
\hline Osmolality, mOsm/kg $\mathrm{H}_{2} \mathrm{O}$ & $284.0(4.6)$ & $275.4(1.8)$ \\
\hline Glucose, $\mathrm{mM}$ & $6.74(0.37)$ & $6.11(0.43)$ \\
\hline Lactate, $\mathrm{mM}$ & $4.71(0.67)$ & $3.81(0.85)$ \\
\hline Creatinine, mg/dl & $0.68(0.06)$ & $0.55(0.04)$ \\
\hline Albumin, $\mathrm{g} / \mathrm{L}$ & $32.8(1.6)$ & $34.5(1.4)$ \\
\hline Protein, g/L & $59.3(2.4)$ & $62.2(2.9)$ \\
\hline SGOT $\mu \mathrm{u} . \mathrm{L}^{-1}$ & $798(422)$ & $387(106)$ \\
\hline SGPT u/L & $283(158)$ & $119(28)$ \\
\hline PT, seconds & $12.0(0.7)$ & $11.5(0.7)$ \\
\hline aPTT, seconds & $42.0(4.5)$ & $36.6(2.4)$ \\
\hline D-dimer ng/ml & $627(198)$ & $455(85)$ \\
\hline Fibrinogen, mg/L & $163.7(14.6)$ & $154.3(16.7)$ \\
\hline
\end{tabular}

treatment in terms of nutritional status, severity of disease, or baseline parameters.

\section{Initial shock treatment and outcome}

As shown in Table 3, no statistical difference was found in the success rate of a single bolus infusion $(P>0.99)$ or in shock recurrence within the first 12 hours $(P=0.14)$.
Table 3 Randomization, treatment, and evolution of DSS: comparison between HSL and RL

\begin{tabular}{llll}
\hline Patients included & $\mathbf{5 0}$ & \\
\cline { 2 - 3 } Randomization & $\mathbf{H S L}$ & $\mathbf{R L}$ & $\boldsymbol{P}^{*}$ \\
\hline Patients randomized & 25 & 25 & \\
Patients withdrawn & 1 & 3 & 0.60 \\
Patients studied & 24 & 22 &
\end{tabular}

Per protocol analysis $(n=46)$

Initial shock treatment (number of patients)

$\begin{array}{llll}\text { One bolus/two boluses } & 18 / 6 & 17 / 5 & >0.99 \\ \text { HES infusions } & 4 & 1 & 0.30\end{array}$

Number of recurrent shocks within the first 12 hours (number of patients)

$\begin{array}{llll}\text { Yes/No } & 7 / 17 & 2 / 20 & 0.14 \\ \text { HES infusions } & 1 & 0 & 0.48 \\ \text { Total HES infusions (24 hours) } & 10 & 1 & 0.005 \\ \text { Concomitant therapies } & & & \end{array}$

Concomitant therapies

\begin{tabular}{llll} 
Blood products & & & \\
Thrombocytes & 1 & 4 & 0.18 \\
Cryoprecipitate & 0 & 2 & 0.22 \\
Fresh frozen plasma & 1 & 3 & 0.34 \\
Antibiotics & 7 & 4 & 0.60 \\
Furosemide & 3 & 3 & $>0.99$ \\
Catecholamines & 1 & 1 & $>0.99$ \\
Antipyretic & 6 & 1 & 0.13 \\
Otal colloid (HES + plasma) (24 hours) & 11 & 4 & 0.06 \\
Intent-to-treat analysis ( $n=50)$ & & & \\
Outcome & & & \\
Recovery & 22 & 20 & 0.70 \\
Forced discharge & 2 & 2 & $>0.99$ \\
Death & 1 & 3 & 0.60 \\
Adverse events/complications & & & \\
DIC & 3 & 5 & 0.70 \\
Encephalopathy & 3 & 3 & $>0.99$ \\
Respiratory distress syndrome & 1 & 0 & $>0.99$ \\
Acute liver failure & 0 & 2 & 0.47 \\
\hline
\end{tabular}

*Fisher Exact test.

The needs of HES administration for initial shock treatment or shock recurrence within the first 12 hours were not different $(P=0.30$ and $P=0.48$ for initial and recurrent shock, respectively). However, HES infusion was more frequently used during the follow-up period (T12 to T24) in the HSL group (5 versus 0 ), leading to a significantly more frequent total HES administration (intervention and follow-up periods) in the HSL group (10 versus 1, $P=0.005)$.

No difference was noticed regarding the outcome. The full recovery rate was similar in the two groups $(P=0.70)$. Two patients in each group left the hospital on hospital 
discharge against medical advice after the intervention period. One versus three people died in the HSL and RL groups, respectively $(P=0.60)$. All four died because of irreversible/terminal shock and multiorgan failures with disseminated intravascular coagulation.

Concomitant therapies did not significantly differ between the two groups (Table 3). However, it could be underlined that, due to the occurrence of hematologic disorder, blood products (that is, thrombocytes, cryoprecipitate, and fresh frozen plasma) were required for 0ne and five patients in the HSL and RL groups, respectively $(P=0.09$, Fisher Exact test), corresponding to two and nine blood products in the HSL and RL groups, respectively. Note that the frequency of use of colloids (HES + fresh frozen plasma) was not significantly different in the two groups.

\section{Comparison of the two fluid regimens on clinical} parameters, intravascular volume expansion, and fluid balance

As shown in Figure 3, systolic blood pressure had improved very significantly at the end of the bolus infusion $(P<0.0001)$ in both groups. This improvement persisted through the intervention and follow-up periods in both groups, with no difference between the two groups $(P=0.90)$. Hematocrit decreased significantly $(P<0.0001)$ in both groups, with no interaction between time and groups. Note that no patient received red cell packs. The urinary output rate (not shown) increased immediately after the beginning of fluid administration $(P<0.0001)$, with a more-pronounced effect in the RL group $(P=0.007)$.

According to the protocol, patients in the RL group received much more fluid than those in the HSL group. The difference increased with time during the intervention period, reaching a four- to fivefold higher intake in the RL group than in the HSL group after 12 hours $(115.9 \pm 3.8$ versus $26.2 \pm 2.9 \mathrm{ml} / \mathrm{kg} / 12 \mathrm{~h}$, for $\mathrm{RL}$ and HSL, respectively, $P<0.0001$ ). During the follow-up period, changes in fluid intake were parallel, as both groups then received the same treatment. Cumulative urine output was slightly but significantly $(P=0.018)$ higher in the RL group. However, as shown in Figure 4, the difference in fluid balance between the two groups was significant $(P<0.0001)$. The RL group accumulated $107 \pm 7 \mathrm{ml} / \mathrm{kg} / 24 \mathrm{~h}$, whereas the HSL group accumulated only $35 \pm 10 \mathrm{ml} / \mathrm{kg} / 24 \mathrm{~h}$. Note that Figure 4 takes into account all the fluids infused (crystalloids, HES, and concomitant therapies, including fresh frozen plasma). Interestingly, at the end of the intervention period (H12), when the initial shock had already been successfully treated for a couple of hours in the two groups, the fluid balance did not differ from zero in the HSL group $(-0.2 \pm 0.2 \mathrm{ml} / \mathrm{kg} / 12 \mathrm{~h} ; P=0.95)$, whereas it was positive in the RL group $(+75.9 \pm 6.0 \mathrm{ml} / \mathrm{kg} / 12 \mathrm{~h}$; $P<0.0001)$. In other words, the fluid balance became positive in the HSL group only after these patients had been shifted from HSL to RL.

\section{○ RL \\ - HSL}

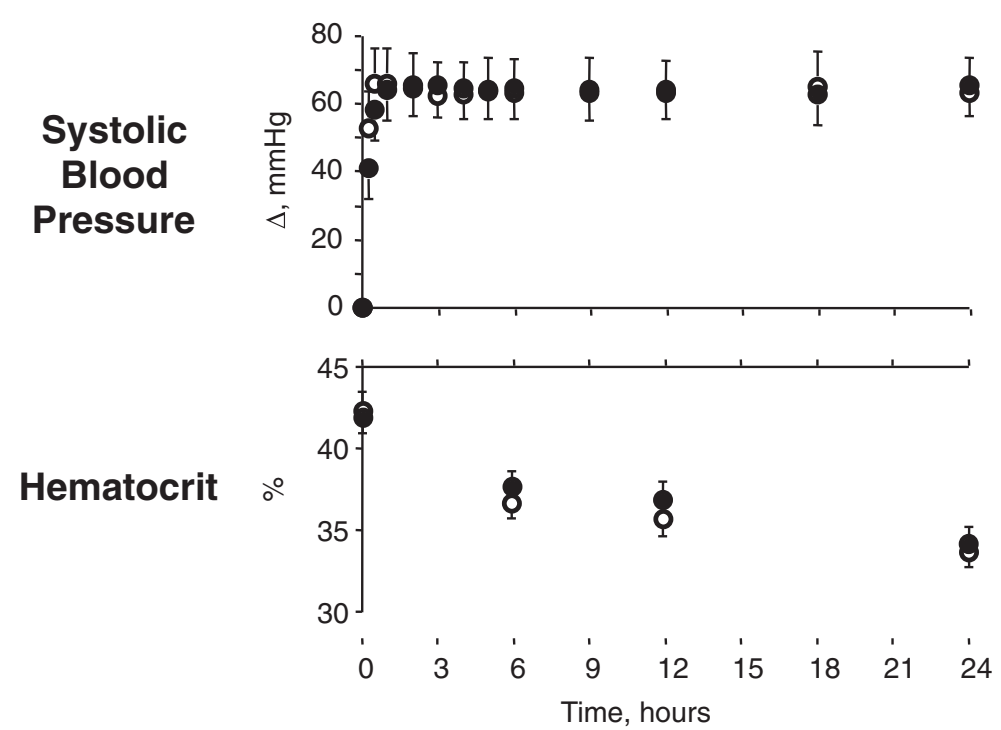

Figure 3 Effect of treatments on systolic blood pressure and hematocrit. Open circles, RL; solid circles, HSL. 


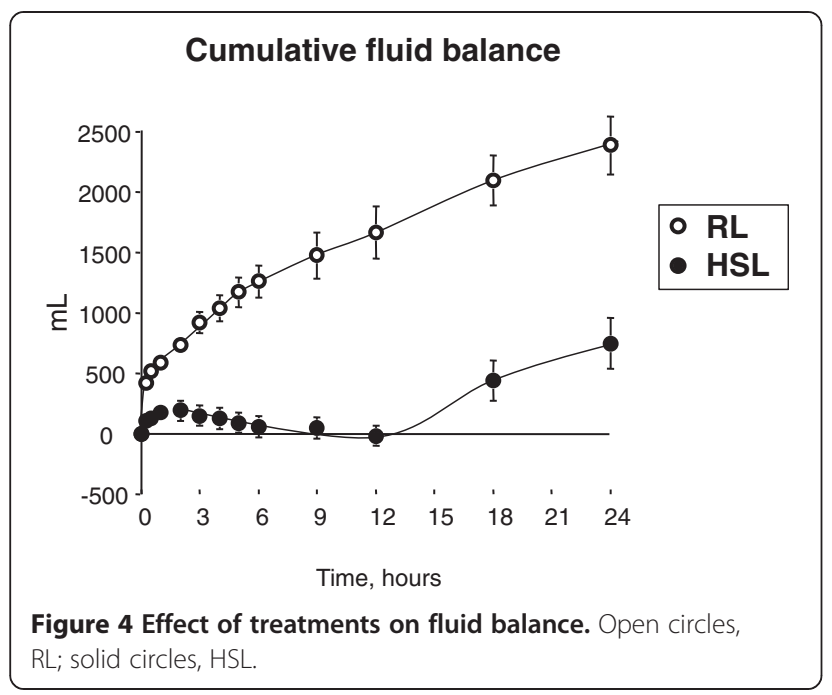

\section{Comparison of the two fluid regimens on biologic parameters}

The main biologic parameters are shown in Table 4, before intervention, at hours 6, 12 (end of intervention), and 24 (end of follow-up period). Venous blood $\mathrm{pH}$ increased with both treatments during the intervention period, with a higher increase in the HSL than in the RL group. Increase in bicarbonate also was greater in the HSL group. No difference between the two treatments was found on plasma sodium concentration. Plasma potassium concentration decreased over time in both groups, with a larger decrease in the HSL group. Interestingly, plasma chloride concentration significantly decreased between T0 and T12 in the HSL group and then increased during the follow-up period, whereas it continuously increased in the RL group. Although the amount of infused lactate was quite substantial in the HSL group, blood lactate concentration did not increase in either the HSL or the RL group. We found no difference between the two groups for plasma osmolality, blood glucose concentration, creatinine, albumin, total protein, or transaminases.

As regards hemostasis, the treatments did not affect PT or aPTT, while they both brought down fibrinogen. As seen in Figure 5, D-dimer did not significantly change $(P=0.7701)$ after 24 hours in the RL group, whereas it decreased in the HSL group $(P=0.0468)$, the difference between the two groups at the $24^{\text {th }}$ hour remaining insignificant, however $(P=0.2117)$. sVCAM-1 did not change in the RL group after 48 hours $(P=0.7089)$, whereas it significantly and continuously decreased in the HSL group $(P=0.0013$ between T0 and T24, $P=0.0116$ between T24 and T48, $P<0.0001$ between T0 and T48), with a significant difference between the two groups at the $48^{\text {th }}$ hour $(P=0.0024)$.

\section{Comparison of the two fluid regimens on sodium and chloride balance}

As seen in Figure 6, cumulative sodium load was positive in both groups at any time and significantly higher in the RL than in the HSL group at T6 $(P=0.0027)$ and T12 $(P=0.0029)$. Indeed, despite a lower sodium concentration in RL than in HSL (Table 1), the more-substantial fluid infusion required led to a superior sodium load in the RL group.

Chloride cumulative balance significantly increased during the intervention $(P=0.0006)$ and the follow-up period $(P=0.0019)$ in the RL group. On the contrary, it significantly decreased $(P=0.0051)$ during the intervention period in the HSL group. During the follow-up period (that is, when RL was infused in both groups), the chloride cumulative balance became positive in the HSL group $(P<0.0001)$, but remained significantly lower than in the RL group $(P<0.0001)$.

\section{Discussion}

It is well acknowledged that the dengue virus can lead to endothelial cell dysfunction responsible for capillary leakage with fluid extravasation from intravascular bed toward interstitial space. This leads to a severe hypovolemic shock in the absence of relevant fluid loss such as vomiting or diarrhea. In the present study, the recovery of such a severe hypovolemic shock without (first 12 hours) or with minimal (24 hours) net expansion of body fluids in the HSL group (see Figure 4) strongly suggests that HSL treatment favored a decrease of capillary leakage, allowing interstitial fluid to reintegrate the vascular bed.

To the best of our knowledge, all the treatments applied to DSS are symptomatic as regards shock or hemorrhagic disorder correction, and etiopathogenic treatments aiming at limiting the inflammatory response or virus invasion are reputed to be unsuccessful. The fact that sVCAM-1 decreased in patients receiving HSL suggests that this treatment might have improved the endothelial cell function.

Quite obviously, the plasma-expander effect of HSL might be related to its hyperosmolarity because a similar effect has been reported with hypertonic saline [17-19]. However, although HSL is hyperosmolar (see Table 1), it is less hypertonic than a sodium-chloride solution with the same osmolarity, because the monocarboxylate carrier allows lactate to cross the cellular plasma membrane [20]. In other words, lactate is expected to leave the intravascular bed to spread inside the cells. In agreement with such a property, lactate concentration did not increase in the HSL group.

Once into the cell, lactate is rapidly metabolized (mainly in glucose or in $\mathrm{CO}_{2}$ plus $\mathrm{H}_{2} \mathrm{O}$ ), whereas $\mathrm{Na}^{+}$is eliminated in urine. However, to maintain urine electroneutrality, negative charges must be eliminated with $\mathrm{Na}^{+}$, 
Table 4 Evolution of blood parameters at 0, 6, 12, and 24 hours after initiation of shock treatment expressed as mean (SEM)

\begin{tabular}{|c|c|c|c|c|c|c|c|c|}
\hline & Treatment & T0 & T6 & $\mathrm{T} 12$ & T24 & $P$ treatment & $P$ time & $P$ interaction \\
\hline \multirow[t]{2}{*}{ Leukocytes, $\mathrm{mm}^{-3}$} & HSL & $6,217(854)$ & $5,600(566)$ & $6,665(698)$ & $7,100(764)$ & 0.862 & 0.001 & 0.844 \\
\hline & $\mathrm{RL}$ & $6,000(755)$ & $5,805(842)$ & $6,623(816)$ & $7,864(1,016)$ & & & \\
\hline \multirow[t]{2}{*}{ Thrombocytes, $\mathrm{mm}^{-3}$} & HSL & $47,042(7,693)$ & $44,583(6,102)$ & $40,348(6,001)$ & $48,773(5,817)$ & 0.297 & 0.016 & 0.529 \\
\hline & $\mathrm{RL}$ & $59,409(7,421)$ & $48,727(5,870)$ & $50,455(6,583)$ & $55,909(4,867)$ & & & \\
\hline \multirow[t]{2}{*}{$\mathrm{pH}$ (venous) } & HSL & $7.40(0.03)$ & $7.50(0.01)$ & $7.50(0.02)$ & $7.46(0.01)$ & $<0.0001$ & $<0.0001$ & 0.100 \\
\hline & $\mathrm{RL}$ & $7.37(0.02)$ & $7.40(0.01)$ & $7.41(0.01)$ & $7.39(0.01)$ & & & \\
\hline \multirow[t]{2}{*}{$\mathrm{CO}_{3} \mathrm{H}^{-}$(venous), $\mathrm{mM}$} & HSL & $15.20(0.87)$ & $21.56(1.04)$ & $26.53(1.19)$ & $25.18(0.73)$ & $<0.0001$ & $<0.0001$ & $<0.0001$ \\
\hline & $\mathrm{RL}$ & $13.76(0.72)$ & $15.21(0.86)$ & $16.94(0.72)$ & $19.35(0.85)$ & & & \\
\hline \multirow[t]{2}{*}{$\mathrm{Na}, \mathrm{mM}$} & $\mathrm{HSL}$ & $129.8(1.2)$ & $129.8(1.2)$ & $130.0(1.3)$ & $130.6(1.3)$ & 0.935 & 0.013 & 0.081 \\
\hline & $\mathrm{RL}$ & $128.1(0.9)$ & $129.0(1.0)$ & $130.3(0.8)$ & $132.7(1.3)$ & & & \\
\hline \multirow[t]{2}{*}{$\mathrm{K}, \mathrm{mM}$} & HSL & $4.36(0.14)$ & $3.42(0.13)$ & $3.23(0.11)$ & $3.18(0.11)$ & $<0.0001$ & $<0.0001$ & 0.001 \\
\hline & $\mathrm{RL}$ & $4.64(0.17)$ & $4.26(0.10)$ & $4.23(0.16)$ & $4.28(0.15)$ & & & \\
\hline \multirow[t]{2}{*}{$\mathrm{Cl}, \mathrm{mM}$} & HSL & $94.3(1.3)$ & $90.5(1.2)$ & $89.5(1.5)$ & $92.5(1.1)$ & $<0.0001$ & 0.003 & $<0.0001$ \\
\hline & $\mathrm{RL}$ & $95.8(1.1)$ & $97.6(1.0)$ & $99.6(1.1)$ & $100.9(0.9)$ & & & \\
\hline \multirow[t]{2}{*}{ Osmolality, mOsm/Kg $\mathrm{H}_{2} \mathrm{O}$} & HSL & $284.0(4.6)$ & $277.9(2.2)$ & $278.5(2.6)$ & $276.4(2.2)$ & 0.240 & 0.416 & 0.104 \\
\hline & $\mathrm{RL}$ & $275.4(1.8)$ & $274.2(2.4)$ & $275.2(1.5)$ & 279.5 (2.6) & & & \\
\hline \multirow[t]{2}{*}{ Glucose, mM } & $\mathrm{HSL}$ & $6.74(0.37)$ & $6.56(0.27)$ & $6.60(0.39)$ & $5.72(0.35)$ & 0.003 & 0.001 & 0.355 \\
\hline & $\mathrm{RL}$ & $6.11(0.43)$ & $5.14(0.27)$ & $5.35(0.33)$ & $4.85(0.29)$ & & & \\
\hline \multirow[t]{2}{*}{ Lactate, mM } & HSL & $4.71(0.67)$ & $2.94(0.41)$ & $2.93(0.32)$ & $1.65(0.20)$ & 0.313 & $<0.0001$ & 0.183 \\
\hline & $\mathrm{RL}$ & $3.81(0.85)$ & $1.87(0.30)$ & $2.11(0.44)$ & $2.24(0.54)$ & & & \\
\hline \multirow[t]{2}{*}{ Creatinine, $\mathrm{mg} / \mathrm{dl}$} & HSL & $0.677(0.063)$ & $0.569(0.066)$ & $0.631(0.088)$ & $0.607(0.105)$ & 0.070 & $<0.0001$ & 0.552 \\
\hline & $\mathrm{RL}$ & 0.549 (0.039) & $0.440(0.023)$ & $0.466(0.030)$ & $0.416(0.023)$ & & & \\
\hline \multirow[t]{2}{*}{ Albumin, $g / L$} & HSL & $32.8(1.6)$ & $29.5(1.1)$ & $28.5(1.1)$ & $26.5(0.9)$ & 0.695 & $<0.0001$ & 0.287 \\
\hline & $\mathrm{RL}$ & $34.5(1.4)$ & $28.5(0.8)$ & $28.5(0.7)$ & $27.6(0.9)$ & & & \\
\hline \multirow[t]{2}{*}{ Protein, g/L } & HSL & $59.3(2.4)$ & $50.7(2.3)$ & $48.5(2.6)$ & $48.0(1.8)$ & 0.264 & $<0.0001$ & 0.990 \\
\hline & $\mathrm{RL}$ & $62.2(2.9)$ & $53.1(1.8)$ & $51.3(1.3)$ & $50.2(1.6)$ & & & \\
\hline \multirow[t]{2}{*}{ SGOT u/L } & $\mathrm{HSL}$ & $798(422)$ & 870 (383) & 765 (373) & $503(191)$ & 0.636 & 0.776 & 0.263 \\
\hline & $\mathrm{RL}$ & 387 (106) & $512(229)$ & $631(363)$ & $656(355)$ & & & \\
\hline \multirow[t]{2}{*}{ SGPT u.L $\mathrm{L}^{-1}$} & HSL & $283(158)$ & $258(103)$ & 245 (109) & $185(76)$ & 0.678 & 0.934 & 0.267 \\
\hline & $\mathrm{RL}$ & $118(27)$ & $181(87)$ & $218(122)$ & 229 (119) & & & \\
\hline \multirow[t]{2}{*}{ PT, seconds } & HSL & $12.0(0.7)$ & $12.2(0.8)$ & $12.2(0.6)$ & $11.4(0.5)$ & 0.443 & 0.221 & 0.094 \\
\hline & $\mathrm{RL}$ & $11.5(0.7)$ & $11.4(1.0)$ & $13.6(2.8)$ & $17.8(4.6)$ & & & \\
\hline \multirow[t]{2}{*}{ aPTT, seconds } & HSL & $42.0(4.5)$ & $49.4(4.7)$ & $50.6(4.8)$ & $39.9(2.3)$ & 0.179 & 0.386 & 0.117 \\
\hline & $\mathrm{RL}$ & $36.6(2.4)$ & $39.9(2.5)$ & $38.3(3.4)$ & $44.6(7.9)$ & & & \\
\hline \multirow[t]{2}{*}{ Fibrinogen, mg/L } & $\mathrm{HSL}$ & $163.7(14.6)$ & $123.1(10.9)$ & $131.7(11.1)$ & $124.1(7.2)$ & 0.443 & $<0.0001$ & 0.734 \\
\hline & $\mathrm{RL}$ & $154.2(16.7)$ & $117.6(8.8)$ & 110.5 (7.9) & $118.4(9.6)$ & & & \\
\hline
\end{tabular}

Repeated measures ANOVA between HSL and RL: $P$ treatment, effect of treatment; $P$ time, effect of time; $P$ interaction, interaction between treatment and time.

including $\mathrm{Cl}^{-}$, which results in a net negative chloride balance (see Figure 6). Because chloride loss was dramatically higher than the decrease in plasma chloride concentration (compare Figure 6 with Table 4), the net negative chloride balance was done mostly at the expense of intracellular chloride. Recent data on $\mathrm{Na}^{+}, \mathrm{K}^{+}$, and $\mathrm{Cl}^{-}$co-exchange support a significant role of chloride balance on cell- volume regulation [21-23]. Hypothesizing that the dengue virus leads to endothelial cells swelling that in turn increases endothelium permeability because of changes in the cell shape, we propose that lactate might return the cell volume back to normal, thus correcting capillary leakage. Note that a negative chloride balance and a decrease in cerebral edema have also been reported in 


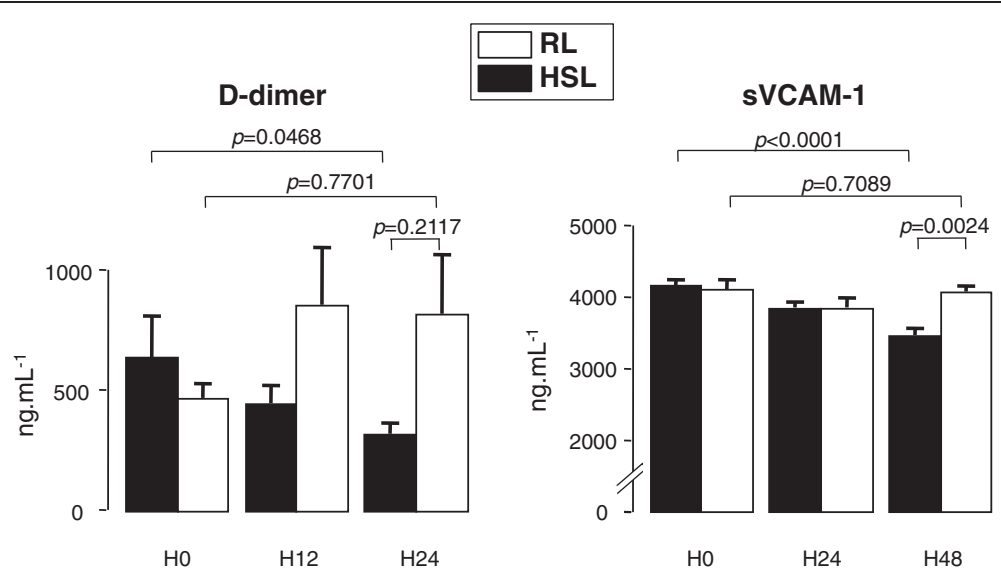

Figure 5 Effect of treatments on homeostasis (D-dimer) and endothelial cell dysfunction (sVCAM-1). Open bars, RL; solid bars, HSL. Comparisons were performed by using Wilcoxon tests for paired data (effect of time) and Mann-Whitney tests for unpaired data (difference between the two groups).

traumatic brain-injured patients infused with sodium lactate [15], whereas HSL has been shown to reduce the number of intracranial hypertensive episodes after severe traumatic brain injury [24].

From these considerations, it appears that HSL may affect intra- versus extracellular fluid distribution in at least two different ways: sodium-related hypertonicity and electrogenic imbalance corrected by chloride efflux from intracellular space.

There are several limitations to this study. The rate of lactate infusion used in this work was based on previous data indicating an average endogenous rate of lactate turnover of 10 to $14 \mathrm{mmol} / \mathrm{kg} / 24 \mathrm{~h}$ and plasma clearance of about 10 to $14 \mathrm{ml} / \mathrm{kg}[25,26]$, as well as on previous administration of lactate to patients $[12,15]$. Note that the initial bolus infusion of HSL ( $5 \mathrm{ml} / \mathrm{kg} \mathrm{BW}$ ) was as effective as the initial bolus infusion of RL ( $20 \mathrm{ml} / \mathrm{kg} \mathrm{BW})$ for the acute shock management, as indicated by a similar initial recovery, including the success rate of a single bolus infusion.

However, the number of patients requiring HES for the initial shock treatment was higher (although not significantly different) in the HSL group. The fluid infusion rate of HSL after boluses $(1 \mathrm{ml} / \mathrm{kg} / \mathrm{h})$ or the duration of the study period (during the first 12 hours) may have been underestimated for some patients. Indeed, recurrent shocks were more frequent (although not significantly so) in the HSL group during the study period (first 12 hours). Moreover, HES administration was required during the follow-up period in the HSL group (that is, once sodium lactate infusion had been stopped). This may suggest that a higher rate of fluid infusion after boluses (for instance, $2 \mathrm{ml} / \mathrm{kg} / \mathrm{h}$ ) is required, or that the study period should be extended for some patients. Note, however, that blood

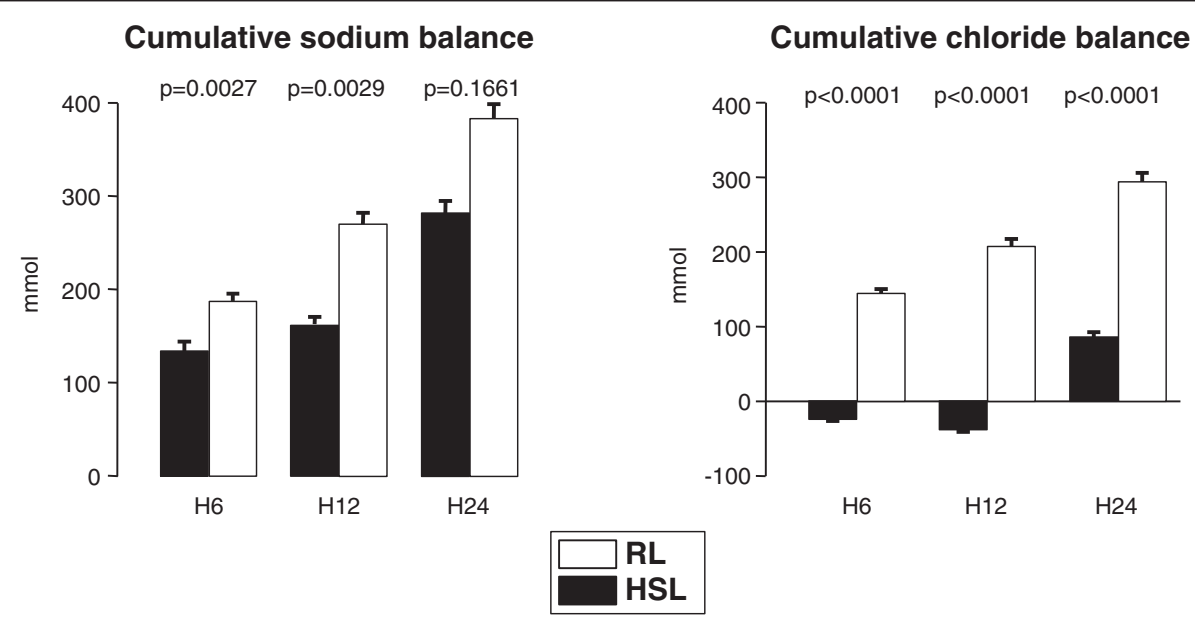

Figure 6 Effect of treatments on sodium and chloride balance. Open bars, RL; solid bars, HSL. Comparisons were performed by using Mann-Whitney tests. 
products were more frequently used in the RL group, which accounts for a significant volume of perfusion and may play down the difference in HES use between the two groups. Indeed, considering the perfusion of colloids (HES and fresh frozen plasma), no significant difference was noted between the two groups.

The outcome was similar in the two groups, as were the complications and the absence of any treatmentrelated side effect. We noted a slightly higher mortality in the RL group as compared with the HSL group, but this difference was not significant. Indeed, because this study was not powered to evaluate a beneficial outcome (but only the physiological consequences of the two treatments), a large multicentric study would be needed to do so.

\section{Conclusion}

This randomized clinical trial has shown that the use of hyperosmolar sodium-lactate solutions in the Dengue shock syndrome allowed the treatment of such a hypovolemic shock with minimal fluid accumulation. Besides the fact that this treatment helped prevent fluid overload, the reduction of sVCAM may have contributed to the resolution of shock. Despite the preliminary nature of our data, the putative mechanism of action of hyperosmolar sodium-lactate solution is of sufficient interest to justify a large-scale clinical trial.

\section{Key messages}

- Hyperosmolar sodium-lactate solutions allowed the correction of dengue shock syndrome with minimal fluid overload.

- This strongly suggests that hyperosmolar sodium-lactate favored a decrease of capillary leakage, allowing interstitial fluid to reintegrate the vascular bed.

\begin{abstract}
Abbreviations
aPTT: Activated partial thromboplastin time; DHF: Dengue hemorrhagic fever; DIC: disseminated intravascular coagulation; DSS: Dengue shock syndrome; GCS: Glasgow coma score; HES: hydroxyl-ethyl starch; HSL: hypertonic sodium lactate solution; PT: prothrombin time; RL: Ringer lactate; SVCAM-1: soluble vascular cell adhesion molecule-1; WHO: World Health Organization.

\section{Competing interests}

The late Professor Xavier Leverve was a member of the Innogene International Scientific Board Advisors.

The other authors confirm that they have no commercial or other associations that might generate a conflict of interest in connection with the submitted article.
\end{abstract}

\section{Authors' contributions}

DHS participated in the design of the study, carried out the acquisition of data, and helped to draft the manuscript. TES conceived of the study, participated in its design and coordination, and helped to draft the manuscript. AMS participated in the design of the study, carried out the acquisition of data, and helped to draft the manuscript. PSI participated in the design of the study, carried out the acquisition of data, and helped to draft the manuscript. DS participated in the design of the study, carried out the acquisition of data, and helped to draft the manuscript. HR participated in the design of the study, performed the statistical analysis, and helped to draft the manuscript. $\mathrm{Cl}$ analyzed and interpreted the data, and participated in the writing of the manuscript. EF analyzed and interpreted the data, and participated in the writing of the manuscript. XML conceived of the study, participated in its design and coordination, and helped to draft the manuscript. All authors, except late Professor XML and late Professor TES, read and approved the final manuscript. We thank Christophe Cottet for the English corrections to this manuscript.

\section{Acknowledgements}

This study was supported by a grant from Innogene Kalbiotech, Pte. Ltd., 24 Raffles Place 27 - 06 Clifford Centre, Singapore 048621. This support served for data collection. The funding body played no role in the design of the study, in the analysis and interpretation of the data, in the writing of the manuscript, or in the decision to submit the manuscript for publication. The half-molar sodium-lactate containing solution is patented (WO 2004/ 096204 -11/11/04, Gazette 2004/46) and registered (Totilac $c^{\text {TM}}$ ).

\section{Author details}

'Department of Pediatrics, Padjadjaran University, Bandung, Indonesia. ${ }^{2}$ Department of Pediatrics, Diponegoro University, Semarang, Indonesia. '3BFA - INSERM U1055, Joseph-Fourier University, BP 5338041 Grenoble, Cedex, France. ${ }^{4}$ Service de Réanimation, Nice Sophia-Antipolis University, Nice, France.

Received: 28 January 2014 Accepted: 21 July 2014

Published online: 05 September 2014

\section{References}

1. Halstead SB: Dengue. Lancet 2007, 370:1644-1652.

2. The World Health Organization and the Special Programme for Research and Training in Tropical Diseases (Ed): Dengue guidelines for diagnosis, treatment and control. Geneva: WHO Library Cataloguing-in-Publication Data; 2009.

3. Basu A, Chaturvedi UC: Vascular endothelium: the battlefield of dengue viruses. FEMS Immunol Med Microbiol 2008, 53:287-299.

4. Guzman MG, Kouri G: Dengue: an update. Lancet Infect Dis 2002, 2:33-42.

5. Rajapakse S: Dengue shock. J Emerg Trauma Shock 2011, 4:120-127.

6. Bethell DB, Gamble J, Pham PL, Nguyen MD, Tran TH, Ha TH, Tran TN, Dong TH, Gartside IB, White NJ, Day NP: Noninvasive measurement of microvascular leakage in patients with dengue hemorrhagic fever. Clin Infect Dis 2001, 32:243-253.

7. Koraka P, Murgue B, Deparis X, Van Gorp EC, Setiati TE, Osterhaus AD, Groen J: Elevation of soluble VCAM-1 plasma levels in children with acute dengue virus infection of varying severity. J Med Virol 2004, 72:445-450

8. Murgue B, Cassar O, Deparis X: Plasma concentrations of sVCAM-1 and severity of dengue infections. J Med Virol 2001, 65:97-104.

9. Dung NM, Day NP, Tam DT, Loan HT, Chau HT, Minh LN, Diet TV, Bethell DB, Kneen R, Hien TT, White NJ, Farrar JJ: Fluid replacement in dengue shock syndrome: a randomized, double-blind comparison of four intravenous-fluid regimens. Clin Infect Dis 1999, 29:787-794.

10. Ngo NT, Cao XT, Kneen R, Wills B, Nguyen VM, Nguyen TQ, Chu VT, Nguyen TT, Simpson JA, Solomon T, White NJ, Farrar J: Acute management of dengue shock syndrome: a randomized double-blind comparison of 4 intravenous fluid regimens in the first hour. Clin Infect Dis 2001, 32:204-213.

11. Wills BA, Nguyen MD, Ha TL, Dong TH, Tran $T N$, Le TT, Tran VD, Nguyen $T H$, Nguyen VC, Stepniewska K, White NJ, Farrar JJ: Comparison of three fluid solutions for resuscitation in dengue shock syndrome. N Engl J Med 2005, 353:877-889.

12. Leverve XM, Boon C, Hakim T, Anwar M, Siregar E, Mustafa I: Half-molar sodium-lactate solution has a beneficial effect in patients after coronary artery bypass grafting. Intensive Care Med 2008, 34:1796-1803.

13. Mustafa I, Roth H, Hanafiah A, Hakim T, Anwar M, Siregar E, Leverve XM: Effect of cardiopulmonary bypass on lactate metabolism. Intensive Care Med 2003, 29:1279-1285.

14. Leverve XM, Mustafa I: Lactate: a key metabolite in the intercellular metabolic interplay. Crit Care 2002, 6:284-285. 
15. Ichai C, Armando G, Orban JC, Berthier F, Rami L, Samat-Long C,

Grimaud $D$, Leverve $X$ : Sodium lactate versus mannitol in the treatment of intracranial hypertensive episodes in severe traumatic brain-injured patients. Intensive Care Med 2009, 35:471-479.

16. Faul F, Erdfelder E, Lang AG, Buchner A: G*Power 3: a flexible statistical power analysis program for the social, behavioral, and biomedical sciences. Behav Res Methods 2007, 39:175-191.

17. Rahal L, Garrido AG, Cruz RJ Jr, Silva E, Poli-de-Figueiredo LF: Fluid replacement with hypertonic or isotonic solutions guided by mixed venous oxygen saturation in experimental hypodynamic sepsis. J Trauma 2009, 67:1205-1212

18. Shih CC, Chen SJ, Chen A, Wu JY, Liaw WJ, Wu CC: Therapeutic effects of hypertonic saline on peritonitis-induced septic shock with multiple organ dysfunction syndrome in rats. Crit Care Med 2008, 36:1864-1872.

19. van Haren FM, Sleigh J, Boerma EC, La Pine M, Bahr M, Pickkers P, van der Hoeven JG: Hypertonic fluid administration in patients with septic shock: a prospective randomized controlled pilot study. Shock 2012, 37:268-275.

20. Halestrap AP, Price NT: The proton-linked monocarboxylate transporter (MCT) family: structure, function and regulation. Biochem J 1999, 343:281-299.

21. Chen $\mathrm{H}$, Sun $\mathrm{D}$ : The role of Na-K-Cl co-transporter in cerebral ischemia. Neurol Res 2005, 27:280-286.

22. Jayakumar AR, Norenberg MD: The Na-K-Cl co-transporter in astrocyte swelling. Metab Brain Dis 2010, 25:31-38.

23. Jayakumar AR, Panickar KS, Curtis KM, Tong XY, Moriyama M, Norenberg MD: Na-K-Cl cotransporter-1 in the mechanism of cell swelling in cultured astrocytes after fluid percussion injury. J Neurochem 2011, 117:437-448.

24. Ichai C, Payen JF, Orban JC, Quintard H, Roth H, Legrand R, Francony G, Leverve XM: Half-molar sodium lactate infusion to prevent intracranial hypertensive episodes in severe traumatic brain injured patients: a randomized controlled trial. Intensive Care Med 2013, 39:1413-1422.

25. Chiolero R, Tappy L, Gillet M, Revelly JP, Roth H, Cayeux C, Schneiter P, Leverve X: Effect of major hepatectomy on glucose and lactate metabolism. Ann Surg 1999, 229:505-513.

26. Revelly JP, Tappy L, Martinez A, Bollmann M, Cayeux MC, Berger MM Chiolero RL: Lactate and glucose metabolism in severe sepsis and cardiogenic shock. Crit Care Med 2005, 33:2235-2240.

doi:10.1186/s13054-014-0466-4

Cite this article as: Somasetia et al:: Early resuscitation of dengue shock syndrome in children with hyperosmolar sodium-lactate: a randomized single-blind clinical trial of efficacy and safety. Critical Care 2014 18:466.

\section{Submit your next manuscript to BioMed Central and take full advantage of:}

- Convenient online submission

- Thorough peer review

- No space constraints or color figure charges

- Immediate publication on acceptance

- Inclusion in PubMed, CAS, Scopus and Google Scholar

- Research which is freely available for redistribution

Submit your manuscript at www.biomedcentral.com/submit
Biomed Central 